\title{
10 Employment deconcentration in European metropolitan areas: A comprehensive comparison and policy implications
}

\author{
Martin Dijst ${ }^{1}$ and Carmen Vázquez ${ }^{2}$ \\ ${ }^{1}$ Faculty of Geosciences, Utrecht University; P.O. Box 80115, 3508 TC, Utrecht, \\ The Netherlands \\ ${ }^{2}$ Department of Geography and Planning, Faculty of Humanities, University \\ of Castilla-La Mancha, Avd. los Alfares 44, 16002 Cuenca, Spain
}

\begin{abstract}
This chapter features a cross-national comparison of economic deconcentration in 12 European metropolitan areas analysing two attributes of employment deconcentration: the magnitude, which refers to the scale of deconcentration; and the physical form. The discussion is positioned in the framework of two dimensions of governance systems: welfare-state regime and central-local government relations. Our expectation that deconcentration would take place on a smaller scale and in a more concentrated form in comprehensive welfare state systems than in liberal regimes is confirmed for one decentralized comprehensive welfare state case and three decentralized liberal state metropolitan areas, but not for the other seven cases. Arguments accounting for this mismatch are put forward. In addition, the effects of deconcentration on the quality of life and the impact of policies are discussed
\end{abstract}

Key words: Employment deconcentration, European metropolitan areas, sprawl, governance systems, quality of life

\section{1 \\ Introduction}

All Western countries are developing towards an economic, social, and political network society (Castells, 1996; Graham \& Marvin, 2001). Investments in highquality transport systems together with the implementation of new Information and Communication Technologies (ICT) offer opportunities for changes in the spatial organization of economic activities world wide. Management, research and development, production, services and other economic activities make new trade-offs between the accessibility of information, people and goods, and costs of locations. The same is true for the locational decisions of households, which reflect changes in preferences for dwellings and environments stimulated by new economic and mobility opportunities. As a consequence, new spatial configurations of land uses have been developed (Ingram, 1998), ranging from concentration to deconcentration with various impacts on the quality of life.

The reorganization of economic activities in the form of their deconcentration is a process that has taken place on a large scale in American metropolitan areas (Garreau, 1991; Lang \& Le Furgy, 2003). Various economic activities have also 
found new locations in European metropolitan areas at the edge of central cities and on suburban locations (Parr, 1999, 2003; Kloosterman \& Musterd, 2001; Phelps \& Parsons, 2003; Halbert, 2004; Bontje \& Burdack, 2005). Considering the large differences between North America and Europe in history, political and cultural contexts, and urbanization patterns (Schwanen et al., 2004), we could expect large differences between these Western continents in the scale and form of economic deconcentration. This is one of the main issues we address. In the earlier chapters, we discuss deconcentration in three selected economic sectors and 13 metropolitan areas and their main determinants for the 1990s patterns and processes of employment. What is lacking is a broad cross-national comparison of the case studies that is positioned in the framework of governance types developed in the first chapter. Such a comparison is the main purpose of this chapter.

The comparison of economic deconcentration processes in metropolitan areas is led by two related hypotheses: the multi-dimensional centrality hypothesis and the governance system hypothesis. The first hypothesis is related to the position of cities within economic cycles. The three North European countries, Denmark, the UK, and the Netherlands, represent economically prosperous countries, which underwent globalization and transformation of the economy a long time ago. New windows of opportunities have been created through innovations in transportation and ICT. As shown by Pred (1977), Friedmann (1986), Sassen (1991) and Castells (1996), for example, multinationals in particular are responsible for changes in the locations of production, administration, research and development, and control functions, which lead to the centralization of various activities in particular places and to the specialization of other places in some activities at the expense of others. As a consequence, many production activities have been moved to developing countries, while control, innovation, financial and business activities increasingly dominate the economies of the North European countries. In contrast, Italy and Spain are lagging behind economically. They are experiencing the early stages of economic transformation. The same can be said for the Czech Republic, which experienced a change from a socialist to a capitalist economy in the 1990s. Finally, Israel is a highly-developed country in the Middle East, surrounded by developing countries and under the utmost demographic and political pressures, but which, like the three north European countries, has been experiencing economic transformations for several decades.

We expect that the position of countries and cities in economic cycles will have an impact on the deconcentration processes in the selected metropolitan areas. Using the metaphor of 'centre and periphery' (Wallerstein, 1979) and the idea of different levels of (spatial) aggregation, economic deconcentration can be hypothesised as a phenomenon of multi-dimensional centrality. This statement means that we expect economic deconcentration to occur first and most intensively in leading economic (central) countries, like Denmark, the UK, the Netherlands, and Israel. Within these countries, the largest cities in which the strategic control and organization activities are located experience the greatest pressures on available land, which will cause large-scale deconcentration. Because of their high rents and transportation costs, 
these cities push out certain economic activities to the edge of the central cities or even further away where the trade-off between accessibility and locational costs are more acceptable (Janelle, 1969; Clark, 2000). As a consequence, these processes result in an expanded area of centralization and specialization or the development of a metropolitan area.

This hypothesis is mainly based on the spatial decisions taken by multinationals. However, the opportunities local, regional, national, and international public authorities have for intervention in market processes could also have large impacts on spatial configurations. The impact of governance systems is the subject of the second hypothesis. Based on the work of Esping-Anderson (1990), in chapter 1 we distinguished between two dimensions of governance systems: welfare-state regime and central-local government relations. These two dimensions define four extreme governance systems.

First, the centralized comprehensive welfare-state model, represented by the Dutch cases, is characterized by a strong hierarchy of government levels and centralized detailed planning regulations, and a broad societal consensus over sustainable development.

The second governance type, the decentralized comprehensive welfare state, differs from the centralized version in the sense that local government is more powerful and autonomous functionally and fiscally and that land-use planning is more decentralized and left to regional and local authorities. Although in Denmark land-use planning is centralized (Larsen, 2005), this type of governance system is exemplified by Copenhagen.

The third type of governance system is the centralized liberal system, best exemplified by Britain since Thatcher. The British cases are confronted with centralized compact development policies, but liberal laissez-faire mechanisms provide incentives for public authorities to deviate from the national plans.

Finally, in a fully decentralized liberal system, which can be found in the United States, markets predominate and local authorities have relatively strong political and financial autonomy.

Although the governance systems of south European countries, post-communist countries, and Israel are all very far from the United States prototype of a decentralized liberal state (Larsen, 2005; see also Razin in this book), compared with northern Europe these countries lean towards a decentralized liberal system model. However, the case studies do show variations in governance system. Madrid and Valladolid in Spain can both be characterized by the concentration of decision power at the regional level with strong influences from commercial interests. The governance systems of the cases in the Czech Republic, Italy, and Israel could all be characterized by local autonomous planning highly influenced by market-based actors. It is assumed that the type of governance system has a large impact on economic deconcentration processes. It is expected that, in welfare-state systems, deconcentration is taking place on a smaller scale and is much more concentrated than in liberal regimes. 
In this concluding chapter, we address both hypotheses. Furthermore, based on the comparative analysis, we discuss the main quality-of-life and policy impacts and implications for policy in metropolitan areas in various settings. The next section provides a comparison of employment deconcentration patterns in the selected metropolitan areas that stand to the fore in this book. This comparison is based on the magnitude and spatial form of deconcentration and the leading economic sectors (manufacturing/construction, consumer, and producer services). Although the data, definitions, and methods applied in the countries vary, we have sought to provide more solid foundations for generalizations than the discussions on observations and impressions presented in the former chapters. In the third section, we set these patterns of deconcentration against the governance types to which the cases belong. In section 10.4, we discuss the quality-of-life impacts of employment deconcentration and related planning policies. Finally, the chapter concludes with a discussion of the main findings and policy implications.

\section{2 \\ Employment deconcentration patterns}

\subsection{1}

\section{Methodological approach}

In this section, we analyse data on employment deconcentration processes that took place in the 1990 s in 12 metropolitan areas. Two attributes of employment deconcentration are discussed: the magnitude, which refers to the scale of deconcentration, and the physical form. Employment data have been classified into three economic sectors:

- Consumer services: supermarkets, department stores, travel agencies, hairdressers, public transport companies, and post offices

- Manufacturing and construction: producers of cars, textiles, beverages, metal, furniture, and so forth, and construction companies

- Producer services: companies working in finance, accountancy, and advertising.

Besides development in employment in these three economic sectors, the sum of employment in these three sectors ('total') has been analysed separately.

The analysis of the form of deconcentration is based on a subdivision of the metropolitan areas into concentric zones starting from the centre of the central city. This subdivision resulted in four functional zones:

- $\mathrm{CBD}$ or centre of the central city

- The rest of central city

- Inner suburban ring

- Outer suburban ring. 
This quantitative approach is supplemented by qualitative observations on the sprawl and clusters of deconcentrated land uses taken from the national chapters in this book.

A comparison of the countries is a useful task, but not one that is easy to accomplish. The countries show wide variations in the availability of data (substantial variations in the level of economic and spatial disaggregation, for example), the definitions of variables, and the methodology applied. For example, the data from the Czech Republic only allowed a distinction to be drawn between two zones: the outer suburban zone and the central city/inner suburban zone. For ChietiPescara (Italy), Valladolid (Spain), Copenhagen (Denmark) and Tel Aviv (Israel) the central city could not be divided into a centre and the rest of the central city. As a consequence, not all cases are included in some tables and figures, which means that the results of this comparative analysis should be interpreted as indicative for employment deconcentration processes.

\subsection{2}

\section{Developments in growth}

The scale of economic growth experienced in the 1990s in each metropolitan area is the subject of Table 10.1. As this Table illustrates, by far the largest growth in employment took place in the Dutch case studies, the Northwing of the Randstad and Breda. In this period, the growth of the Dutch economy was well above that in other European countries and the US (Bogaerts et al. in this book). In terms of employment growth, the Italian cases and Brno have lagged behind the other countries. In all the cities the most important driver for the spatial reconfiguration of economic land use was the producer services. This growth was again especially high in the Dutch cases, but Madrid also shows a very large increase in the number of jobs in this economic sector. In comparison with producer services employment in consumer services has grown less. The exceptions are the Czech Republic, Israel, and the UK. The earlier chapters show that expansion in retailing in these countries is caused by various factors. In the Czech Republic, the transition of the former socialist system into a market economy attracted new (foreign) investments in big-box hypermarkets. The rapid demographic growth caused by the migration of Jews and weakened central controls can be seen as the main drivers for job growth in retailing in Israel. The planning efforts in developing shopping centres could explain the growth in retail employment in the UK cases.

Table 10.1 informs us also about the magnitude of economic deconcentration. This is operationalized by the growth of employment in the suburban zone (the sum of the inner and outer suburban rings) as a percentage of total metropolitan employment in approximately 1990. The figures clearly show that the scale of deconcentration was relatively large in the northern countries Denmark, the UK, and the Netherlands and also in Israel, which seems to be in accordance with the multi-dimensional centrality hypothesis. The large scale of deconcentration in Madrid was not expected. In the past two decades, Madrid has undergone a process 


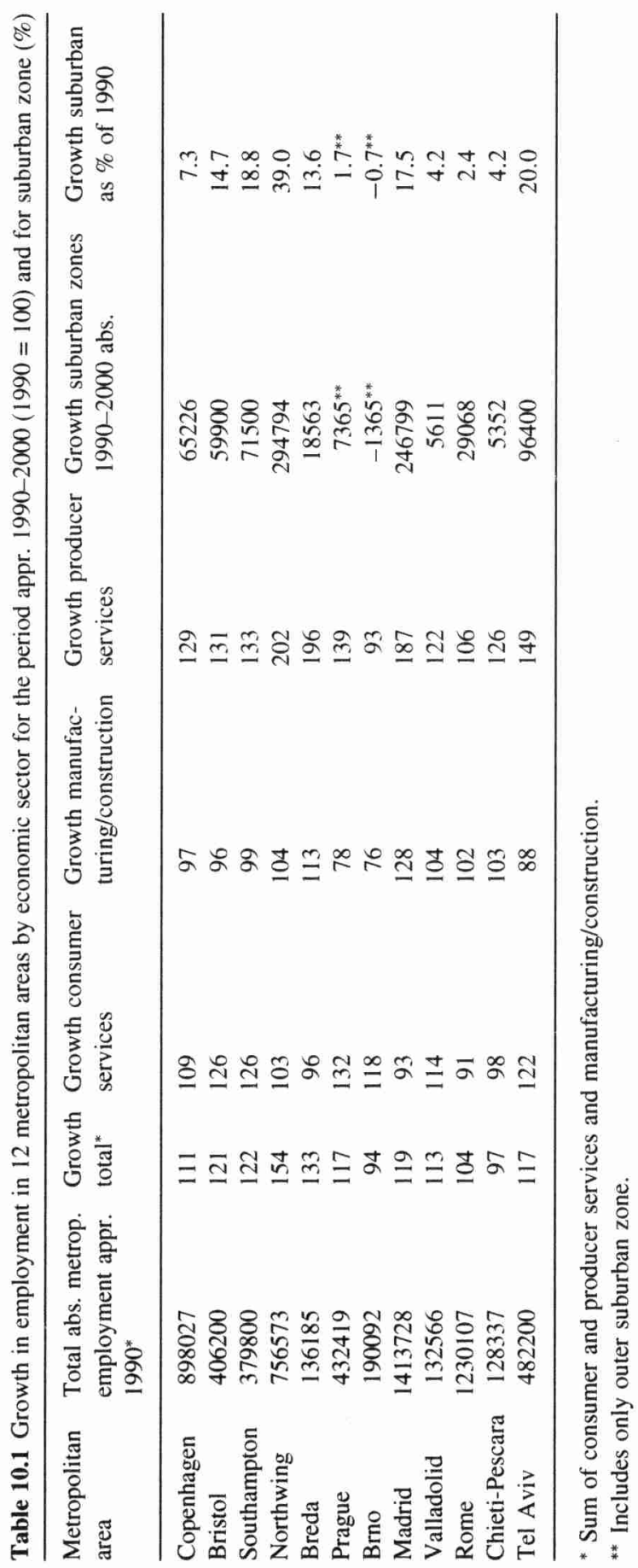


of economic internationalization and high economic growth; the spatial pattern is led by market forces and regional planning policies favouring municipalities located mostly in the southwest of Madrid (Valenzuela et al. in this book). The extent of deconcentration in the Dutch Northwing might be surprising for a country perceived as a prototype of central planning and compact urbanism. However, as can be seen from Table 10.1, the total growth of employment in the Northwing is by far the largest, which is difficult to accommodate in the central city alone. Dutch planning has not always been focused on the strengthening of central cities, but has also sought to concentrate urban growth outside the central cities in designated centres (Bogaerts et al. in this book). In the UK, deconcentration has been influenced by labour-market and real-estate conditions, especially in Bristol (Smith in this book). Finally, in Tel Aviv, locations were sought for economic activities along major highways and highway junctions with competitive land prices and high accessibility (Razin \& Shachar in this book).

In Figure 10.1, the growth in employment in each ring is shown for all the metropolitan areas. From this figure we notice large variations in the spatial configuration of employment growth. For total employment growth in all metropolitan areas, the differences between the functional zones is largest in Spain and the Netherlands and the least in the cases of the Czech Republic, Denmark and Italy. Although, less strongly than in the suburban zones, in general employment is expanding in the central cities. Also, most centres of the central cities show a stable number of jobs or even a (small) growth (in Bristol and Southampton for example). In Madrid, Valladolid, Tel Aviv and Breda, the growth in the outer suburban ring is substantial.

What differences do we observe in the spatial distribution of growth between the economic sectors? The change in employment in consumer services in the functional zones is mainly a reflection of the decline in population in the central cities and growth of the suburban population. In the Netherlands, Italy, and Denmark few differences between the rings can be observed. On the other hand, suburban employment growth in this sector is substantial in Madrid, Prague, Bristol, Southampton, and Tel Aviv. This growth is explained not only by residential suburbanization, but also by changes in retailing policies with less control over or even the stimulation of the expansion of retailing outside the central cities. For example, Israel is characterized by intense competition in terms of land, rent, and legality between local authorities and developers over retail establishments (Razin \& Shachar in this book). In the Czech Republic, the foreign investments in hypermarkets in combination with an aversion to central planning stimulated the suburban growth in retail employment (Sýkora \& Ouřednícek in this book).

In general, owing to the nuisances associated with some facilities, the downtown areas of the central cities are not kindly disposed to manufacturing/construction. Although in general the centres lost employment in the 1990s, in the centres of Madrid and Bristol this sector showed an increase in the number of jobs. In Madrid's case it was construction, not the manufacturing sector that led the deconcentration process; in fact, employment in the construction sector shows the 


\section{Employment changes in functional zones (1)}
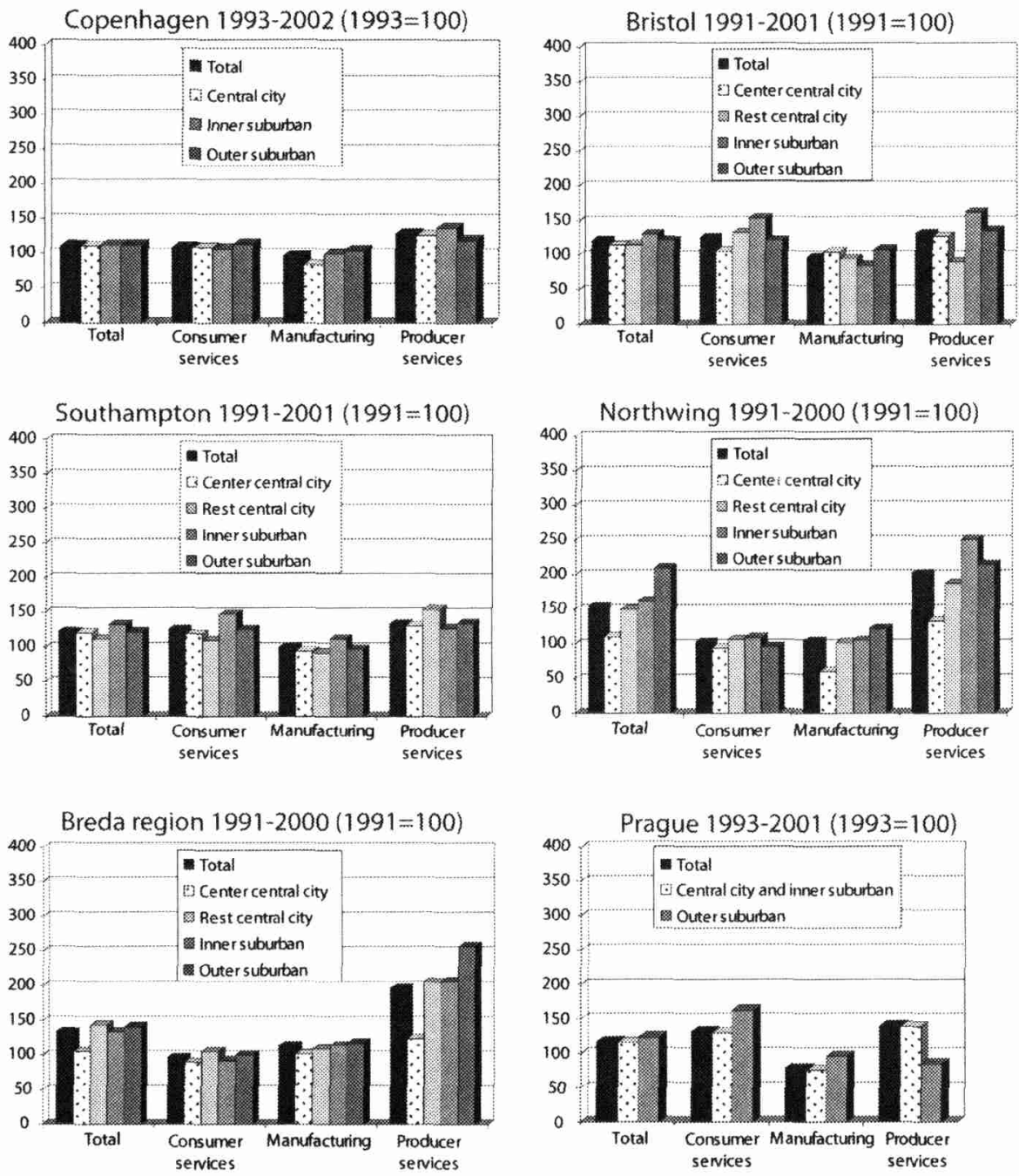

Fig. 10.1 Development in employment growth for functional urban zones by economic sector in 12 metropolitan areas

highest rate of increase during the whole period and its evolution is a reliable image of the dynamism and expansion of the districts/municipalities within the Madrid metropolitan area. In Bristol, the evidence suggests that manufacturing experienced a relative deconcentration within the $30 \mathrm{~km}$ zone, even though employment also continued to grow within the city-centre area. This pattern has been complicated by the contraction of employment in aircraft manufacture in Bristol's north fringe as a 


\section{Employment changes in functional zones (2)}
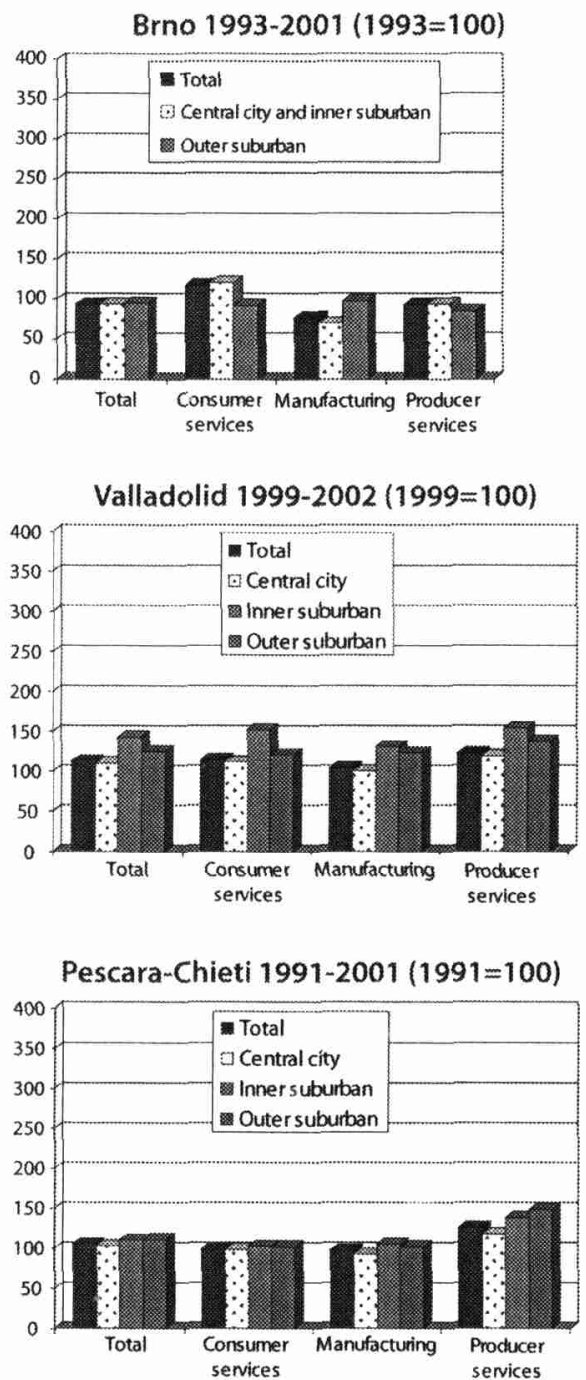
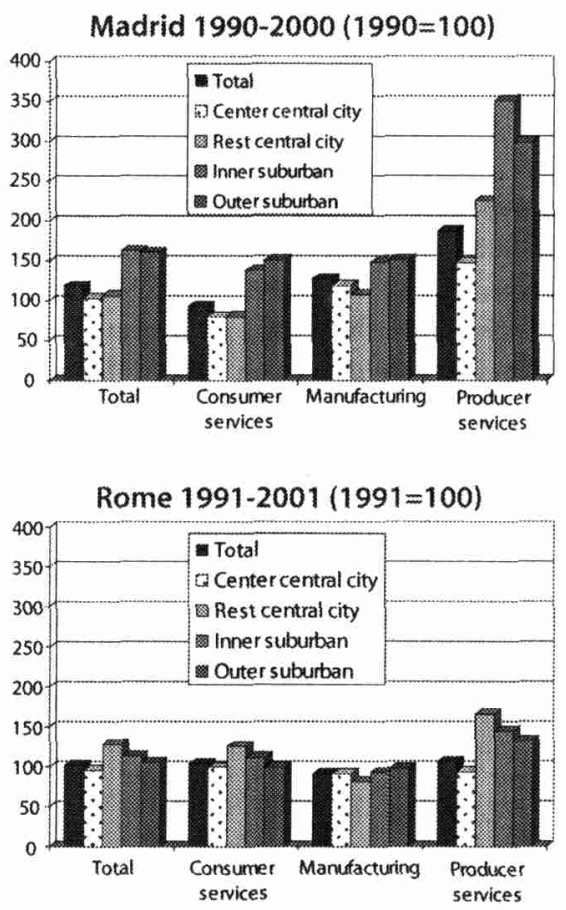

Tel-Aviv 1995-2002 $(1995=100)$

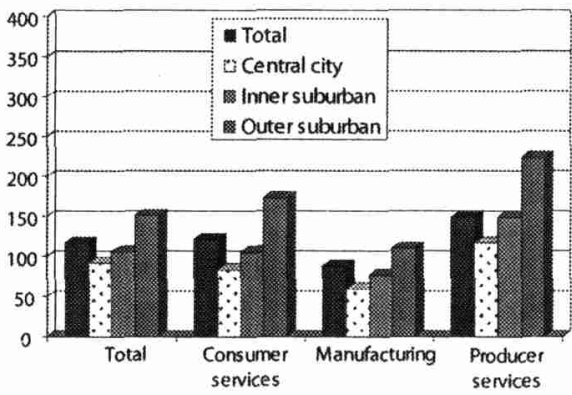

Fig. 10.1 continued

result of the end of the cold war in the early 1990s and the changing structure of the air transport industry in the late 1990s. With the exception of Italy, the locations that have shown an increase in popularity for employment in manufacturing are the outer and, to a lesser extent, the inner suburban rings. This spatial pattern also reflects the changes in the locational preferences of manufacturers for suitable and 
sufficient land at accessible locations and the greater emphasis that has been put on the quality of life by the public and planning authorities. In Italy, the employment growth was larger in the rest of the central city. In Rome, historically the small and medium-sized companies were located along a few axes in the metropolitan area (Montanari et al. in this book).

Although, compared with consumer services and manufacturing, the growth in the number of jobs in the producer services in the downtown areas of the central cities can be said to have been substantial, these urban areas are surpassed by the suburban rings. Producer services have found their preferred place of location in the inner suburban ring, as in the Northwing, Madrid, Valladolid, Copenhagen, and Bristol, and the urban ring of the central cities in Rome and Southampton. The outer suburban rings attracted a lot of jobs in Breda, Chieti-Pescara, and Tel Aviv.

We can conclude that, in general, growth in employment is largest in the ring that encircles the urban centres (Rome) and in the inner suburban ring (Madrid, Valladolid, Bristol, Southampton, and Northwing Randstad). Employment growth in the outer suburban rings is relatively large in Madrid, Tel Aviv, and Breda. Differentiated by economic sector, we found that the growth in employment in the manufacturing/construction sector showed the greatest deconcentration. The least deconcentrated sector in terms of growth was the producer services, while the consumer services took an intermediate position.

\subsection{3}

\section{Development in positions of functional zones}

So far, we have discussed the job growth and the magnitude of economic deconcentration in the entire metropolitan area and various rings of this area for total employment and by economic sector. In order to characterize the form of deconcentration processes in these metropolitan areas, this picture is complemented by an analysis of the change in position of each functional zone within the metropolitan area to which it belongs. This analysis is the subject of this section. To that end, we have calculated the ratios of employment in pairs of functional zones. In Table 10.2, the ratios are presented of successively central city-suburban zones, centre-rest central city, and finally, inner-outer suburban zones. Our data do not allow us to assess whether deconcentration has taken the shape of a concentrated or a scattered form. Qualitative descriptions taken from the national chapters can give some insight into these specific form characteristics.

In the early 1990s, the central cities of the Italian and Spanish cases had the strongest positions in their metropolitan areas. These areas could be characterized as strong monocentric urban systems. This is particularly the case for consumer services and manufacturing/construction. In approximately 1990, in most cases producer services had a strong position in the central cities. In contrast with the Italian and Spanish cases, Copenhagen, the two British cities, and Tel Aviv suburban zones seemed much more important as employment locations than the central city. The Dutch cities took an intermediate position. Table 10.2 shows that, 
Table 10.2 Ratios of total number of employees in central city and suburban zones in appr. 1990 and $2000^{*}$

\begin{tabular}{|c|c|c|c|c|c|c|}
\hline \multirow{2}{*}{$\frac{\text { Functional zone }}{\text { Metropolitan area }}$} & \multicolumn{2}{|c|}{ Central city/suburban } & \multicolumn{2}{|c|}{ Centre/rest central city } & \multicolumn{2}{|c|}{ Inner/outer suburban } \\
\hline & 1990 & 2000 & 1990 & 2000 & 1990 & 2000 \\
\hline Copenhagen & 0.62 & 0.61 & - & - & 1.47 & 1.47 \\
\hline Bristol & 0.67 & 0.62 & 2.65 & 2.64 & 0.75 & 0.81 \\
\hline Southampton & 0.35 & 0.33 & 1.28 & 1.38 & 0.26 & 0.29 \\
\hline Northwing & 0.88 & 0.67 & 0.79 & 0.59 & 3.22 & 2.49 \\
\hline Breda & 0.84 & 0.80 & 0.54 & 0.40 & 1.59 & 1.51 \\
\hline Madrid & 3.39 & 1.99 & 1.67 & 1.62 & 4.88 & 4.96 \\
\hline Valladolid & 8.42 & 6.59 & - & - & 4.30 & 5.03 \\
\hline Rome & 3.72 & 3.32 & 7.83 & 5.86 & 3.03 & 3.27 \\
\hline Chieti-Pescara & 1.52 & 1.41 & - & - & 0.50 & 0.50 \\
\hline Tel Aviv & 0.61 & 0.42 & - & - & 0.73 & 0.51 \\
\hline
\end{tabular}

* Ratios for Prague and Brno could not be calculated (see section 10.2.1)

- No division could be made between the centre and the rest of the central city (see section 10.2.1)

within the central city of Rome, the centre of the town had a dominant employment position, followed at a considerable distance by the centres of Madrid, Bristol, and Southampton. In Madrid and Rome in 1990, employment in the suburban zones was largely concentrated within the inner suburban ring. Copenhagen and the two Dutch cases are also characterized by the relatively limited employment shares of the outer suburban zone, which reflect the effectiveness of their deconcentration policies.

Since 1990, the central city has seen its dominant position in employment diminish in all the selected metropolitan areas. This positional change was most striking for Madrid and Valladolid in Spain, although in both the central cities remain important in terms of employment. In all the countries, the deconcentration trend is most striking for producer services, which have found new locations at the edge of central cities. In general, the deconcentration of manufacturing/construction is rather limited, which indicates that deconcentration took place before the 1990s, as in northern Europe. However, in Italy and Spain this economic sector still seems to find reasonable locations in central cities. In the 1990s, the three northern European countries, Denmark, the UK, and the Netherlands, experienced the least change in position. In these countries the deconcentration processes that had originated some decades before the 1990s continued. The same applies to Tel Aviv. Within the central cities, the position of the centres hardly changed for the two British cases and Madrid. These results for the British cities seem to reflect the impact of the Sequence Approach in planning, which favoured new developments in town centres over other centres (Hills et al., 2005). Large-scale urban renewal in Madrid could keep employment in Madrid (Valenzuela et al. in this book). Downtown Rome lost employment in favour of the rest of the central city in absolute and in particular in relative terms. Nevertheless, this central area of the city still 
dominates, as in the two British cases and Madrid. These four central cities also experienced a strengthening of the position of their inner suburban zones. Together with Copenhagen and the two Dutch cases, in 2000 the supply of jobs in the inner suburban zones of Rome and the Spanish was much higher than in the outer suburban zones. The converse is true for the suburban zones of Chieti-Pescara, Bristol, Southampton, and Tel Aviv.

Based on our observations reported in the last two subsections, we can conclude that, in the 1990s, in the selected metropolitan areas the central cities and, in most cases, also the centres of these cities, lost ground as the main source of jobs in favour of the suburban areas. Nevertheless, in absolute terms job growth in most of these areas continued through the 1990s. The change in the position of the central cities started much earlier in the northern European countries and Israel than in southern and eastern Europe. Furthermore, the scale of deconcentration in the large metropolitan areas of these countries seems more substantial than in the smaller areas. These findings seem to confirm the multi-dimensional centrality hypothesis, which states that deconcentration occurs first and most intensively in the economically leading countries and the largest cities. However, the findings also show that Spain in particular seems to be catching up quickly.

The results also show that the deconcentration processes have taken a rather compact form in The Northwing of the Randstad, Breda, Copenhagen, Rome, Madrid, and Valladolid. However, the growth figures per zone show that the number of jobs in the outer suburban zone of the Spanish cases is increasing rapidly. Employment is deconcentrated at a larger distance from the central city in the small metropolitan area of Chieti-Pescara in Italy, in the UK, and in Tel Aviv. In spite of these changes, the central cities of the Italian and Spanish cases still dominate the metropolitan area and as a consequence can be characterized as monocentric. Although Prague and Brno in the Czech Republic are not mentioned in Table 10.2, our impression is that the same conclusions can be drawn for them. The other metropolitan areas show more polycentric developments. Besides the position within economic cycles, we expect that the type of governance systems also has an impact on the scale of deconcentration and particularly on the form of these spatial reconfigurations. This issue is addressed in the next section.

\section{3}

\section{Deconcentration patterns and governance types}

In this section, we consider the hypothesis that deconcentration is taking place on a smaller scale and is much more concentrated in welfare-state systems than in liberal regimes. Our selected metropolitan areas belong to four different types of governance systems: centralized comprehensive welfare state; decentralized 
comprehensive welfare state; centralized liberal; decentralized liberal. In Table 1.2 of chapter 1, the expected association of these types of governance system and economic deconcentration patterns is shown. In Table 10.3, we set this expectation against the findings from our analysis. The assessment of the magnitude of economic deconcentration is calculated as the employment growth in the suburban zone expressed as a percentage of total employment in the early 1990s (see Table 10.1). The data we have used in this chapter only allow us to define form of deconcentration in terms of the distance of employment from the central city or centre of the central city (see Table 10.2).

As Table 10.3 shows, the confrontation of patterns of employment deconcentration with the governance types to which the countries belong both corroborate and confuse the previous assumptions. Only four cases match our expectations: Copenhagen, Chieti-Pescara, Madrid, and Tel Aviv. The other metropolitan areas deviate from our expectations in magnitude and form of economic deconcentration. Based on the results of earlier chapters, in this section we put forward an interpretation of these results.

Although the Dutch cases fall under the centralized comprehensive welfarestate governance model as expected, the patterns of the Northwing of the Randstad and Breda are much larger than we expected. As explained in section 10.2.2, this size is the result of the enormous growth of employment in the 1990s and the fact that Dutch planning also stimulated growth in designated areas outside the central cities. This growth in the Dutch cases was largely brought about by the expansion of producer services. As a consequence of this growth, the

Table 10.3 The expected relationships between governance system and pattern of economic deconcentration (italics), the confirmed (bold italics) and deviated relations (bold regular)

\begin{tabular}{|c|c|c|c|c|}
\hline \multirow{2}{*}{$\begin{array}{l}\text { Pattern of } \\
\text { economic } \\
\text { deconcentration }\end{array}$} & \multicolumn{4}{|c|}{ Governance system } \\
\hline & $\begin{array}{l}\text { Centralized } \\
\text { comprehensive } \\
\text { welfare state }\end{array}$ & $\begin{array}{l}\text { Decentralized } \\
\text { comprehensive } \\
\text { welfare state }\end{array}$ & $\begin{array}{l}\text { Centralized } \\
\text { liberal }\end{array}$ & $\begin{array}{l}\text { Decentralized } \\
\text { liberal }\end{array}$ \\
\hline $\begin{array}{l}\text { Magnitude and } \\
\text { form }\end{array}$ & $\begin{array}{l}\text { The } \\
\text { Netherlands }\end{array}$ & Denmark & $\begin{array}{l}\text { United } \\
\text { Kingdom }\end{array}$ & $\begin{array}{l}\text { Czech Republic } \\
\text { Israel Italy } \\
\text { Spain }\end{array}$ \\
\hline $\begin{array}{l}\text { Small scale } \\
\text { Concentrated }\end{array}$ & $\begin{array}{l}\text { Northwing } \\
\text { Randstad } \\
\text { Breda }\end{array}$ & Copenhagen & & $\begin{array}{l}\text { Rome Prague } \\
\text { Brno } \\
\text { Valladolid }\end{array}$ \\
\hline $\begin{array}{l}\text { Small-scale Less } \\
\text { concentrated }\end{array}$ & $\begin{array}{l}\text { Northwing } \\
\text { Randstad } \\
\text { Breda }\end{array}$ & Copenhagen & $\begin{array}{l}\text { Bristol } \\
\text { Southampton }\end{array}$ & Chieti-Pescara \\
\hline $\begin{array}{l}\text { Large-scale } \\
\quad \text { Concentrated }\end{array}$ & $\begin{array}{l}\text { Northwing } \\
\text { Randstad } \\
\text { Breda }\end{array}$ & Copenhagen & $\begin{array}{l}\text { Bristol } \\
\text { Southampton }\end{array}$ & Madrid \\
\hline $\begin{array}{l}\text { Large-scale Less } \\
\text { concentrated }\end{array}$ & & & $\begin{array}{l}\text { Bristol } \\
\text { Southampton }\end{array}$ & Tel Aviv \\
\hline
\end{tabular}


competition for scarce space in the central cities of these cases increased, with rising rents as the result. Companies with a high requirement for floor space, such as distribution firms or business administration, have moved to suburban locations (Bogaerts et al. in this book).

The deconcentration pattern of Copenhagen fits the hypothesis reasonably well. The form of deconcentration is concentrated, which is probably a consequence of the centralized land-use planning that we find in the Netherlands. The Danish and Dutch cases have been highly successful in containing urban sprawl. This success is not one which originates from the 1990s it started much earlier in both countries. For decades, the principles of Dutch planning most successful in limiting sprawl are concentration of urbanization and spatial diversity. Various Planning Memorandums have stimulated the channelling of residential growth into suburban or urban centres since the 1960s, and similarly for economic functions in the 1990s. Deconcentrated developments took place in a rather concentrated manner along highways at infrastructure nodes and on designated sites. A new policy of compact urban growth formulated in the Fourth Physical Planning Memorandum stimulated urban growth in existing central cities and on new greenfield sites directly adjacent to the built-up areas of the larger cities (MVROM, 1988). As an important instrument to stimulate compact developments, the Fourth Physical Planning Memorandum (MVROM, 1991) introduced the ABC location policy for firms. This policy was aimed to encourage the location of firms at public transport locations. The intention was to reduce the use of private cars. The extent of the success of this policy is, however, questionable. Many new employment- and visitor-intensive economic developments were located on sites along highways that were not accessible by public transport. High rents and poor accessibility by car at public transport locations, limited support of this policy by private and public actors, and the enormous demand for space were responsible for the disappointing results. A highly successful policy in force since 1973 is Dutch retail policy. This prevented the establishment of out-of-town shopping malls. As a consequence, most shops are still located within the built-up areas of cities and towns and within walking or cycling distance of home for local residents (Evers, 2002). It is, however, expected that in future more extensive and less concentrated forms of economic deconcentration will occur (Bogaerts et al. in this book) as a consequence of the liberalization of policies and the deconcentration of planning power from national authorities to lower administrative levels.

As in the Netherlands, in Denmark the policy options to curb sprawl and employment deconcentration also favour direct land-use planning constraints and equalization mechanisms. In fact, on a regional scale, in Greater Copenhagen urban development has been controlled through a successful comprehensive planning for nearly sixty years. The main principle - the Finger Plan - has been implemented and the development in radial urban fingers along railway lines and with green wedges between the fingers is easy to recognize on a map. In the decades 1960-1980, not all secondary centres outside the city of Copenhagen were developed as planned. The successful centres have mainly become shopping centres. 
However, employment was deconcentrated from Copenhagen to business parks in the periphery, small enclaves in urban areas or in traditional industrial areas, along motorways and relatively isolated sites. The Regional Plan for Greater Copenhagen of 1989 reintroduced and reinterpreted the finger structure. At that time, only half the office floor space constructed in the 1990s in Greater Copenhagen was located within walking distance of a station. The desired balance of power among the three administrative levels, conflicts between planning and sectoral considerations, the interests of individual property owners and the difficulties of brownfield developments have hindered the location policy. However, the strongly-decentralized public sector is ready to undergo some administrative changes; the county units and Greater Copenhagen Authority will be abolished from January 2007 and Denmark's 271 municipalities will be reduced to 98; in such a context, land-use planning will be a matter between the state and the municipalities.

Intermediate levels of policies and patterns of deconcentration, that is to say small-scale less concentrated or large-scale concentrated deconcentration types, could characterize a centralized liberal governance model. However, as Table 10.3 shows, the deconcentration pattern of both Bristol and Southampton can be characterized as large scale and is taking place at a relatively large distance. This pattern does not mean that no employment growth is taking place in the city centres. Compact policies, including those to keep out-of-town retail developments within fixed limits, and the regeneration of centrally-located declining concentrations of economic activities contributed to the growth of employment in the city centres of Bristol and Southampton. However, deconcentration dominated the metropolitan scenc. The integration of public policy interventions within metropolitan areas is made problematic in the UK because of the fragmentation of jurisdictions across the city-regions. Local government reorganization in 1996-97 made matters more difficult at the metropolitan level with further fragmentation of local policy responses in relation to land-use planning, transport, and education. In this context, economic deconcentration is assumed to be part of the urban economic restructuring that has made these city-regions more economically successful, but seems also to have stimulated economic deconcentration in outer suburban zones. This process of deconcentration to the fringes of Bristol and Southampton was also supported by residential deconcentration, followed by employment in consumer services, and the availability of new office space (Smith in this book).

Although the Czech Republic, Israel, Italy, and Spain are certainly very far from the United States prototype of a decentralized liberal state, our impression is that these countries lean towards this model in a comparative European perspective. Based on experiences from the US, it was expected that case studies from these European countries would show more large-scale, less concentrated deconcentration patterns than the countries in northern Europe. Metropolitan areas located in Spain or Italy could have been expected to display a less planned pattern of deconcentration, resulting from loose management practices and low levels of enforcement of laws and regulations. However, less explicit policies towards deconcentration and lower levels of enforcement did produce mixed results concerning 
the magnitude and form of deconcentration. The two largest metropolitan areas, Rome and Madrid, differ in scale of deconcentration, but are both characterized by highly-concentrated forms. These metropolitan areas seem to have retained a strong monocentric employment distribution, mainly reflecting market mechanisms. Only the small metropolitan area of Chieti-Pescara in Italy shows some less concentrated forms of deconcentration.

Formally, the governance system of Italy is characterized by a clear, hierarchical planning system. However, coordination across the various levels is difficult to establish (Larsen, 2005; Montanari et al., in this book). So, other factors seem to be responsible for the concentrated form of deconcentration we find in the capital of Italy. First, the relatively small growth in employment in Rome and even a decline in Chieti-Pescara (Table 10.1) did not put excessive pressure on land use in these metropolitan areas. Second, in Rome the locational decisions of firms are highly influenced by the urban scenery. This city has a historic and environmental heritage of inestimable value, which constitutes the exogenous variable or the main market attribute. As a consequence, there is a centripetal force of attraction. In general, it can be stated that, in Italy, when centres continue to be attractive, they are valued, whereas the peripheries are second best to locate in. In Rome, historically the small and medium-sized companies were located along a few axes in the metropolitan area, but, compared with other European cities, the percentages of employment located in the central city are still high. Deconcentration in the metropolitan area of Rome occurs between the centre and the borders of the central city. The lack of high value in the two centres of Chieti-Pescara has contributed to the deconcentration processes within this metropolitan area. During the last few years in Rome there has been a tendency to recover peripheral buildings and existing spaces through renovation. These policies were intensified and supported by community programmes. Currently, the City Master Plan identifies 18 new urban and metropolitan centres. The underlying goal is the revitalization of the peripheries through "a distribution of central city values throughout the suburbs" (Marcelloni, 2003: 132). The strategy is that of finding peripheral locations within the municipality, not outside it.

Spain only recently became a democracy (1978) and a member of the European Union (1986). Madrid in particular is rapidly developing as an internationalized economy with interests in Europe and Latin-America, thereby undergoing largescale economic deconcentration. The arrival of democracy in Spain in the second half of the $1970 \mathrm{~s}^{1}$ and the shaping of the new Autonomous Community structure ${ }^{2}$ had a negative effect on the survival of the metropolitan development authorities and planning coordination both across and within sectors, and across different government levels. The municipalities together with market forces have left their mark on the spatial configurations of employment. Since the early 1980s, like many other Spanish cities, Madrid has enjoyed an enormous improvement in urban quality. The city's transformation has affected every single sector. The improvements include the configuration of a modern arterial network and one of the best public transport systems in Europe; the protection and refurbishing of buildings; 
the eradication of shanty-towns and areas of sub-standard housing; the creation of over $12 \mathrm{~km}^{2}$ of new residential areas; the restructuring of a substantial part of the municipal periphery; and the improvement of public amenities of all kinds (López de Lucio, 2000). These transformations slowed down the deconcentration of urban functions outside Madrid. Until recently, deconcentration processes in Spanish cities have mainly been residential. However, during the 1990s, a combination of purposeful deconcentration policies and market forces encouraged employment deconcentration in Madrid. Large growth in employment (Table 10.1) and increased prices for real estate and costs for the rehabilitation of obsolete premises in central areas triggered firms to find new locations outside the central city. This deconcentration was further stimulated by public subsidies and tax incentives to spread economic activities, like offices (technological and business parks), consumer (shopping and leisure centres), and public services. The development of new transport infrastructures, which improved accessibility in the metropolitan area, contributed to a gradual erosion of the existing monocentric spatial pattern. Nevertheless, the central city of Madrid still dominates employment opportunities in the metropolitan area. The same is true for Valladolid, where economic deconcentration processes are still at an early stage.

In contrast with Italy and Spain, economic deconcentration in the other Mediterranean country, Israel, is far less concentrated. The rapid demographic growth caused by the migration of Jews and weakened central controls can be seen as the main drivers for this deconcentration pattern. Since the 1990s, an avalanche of more than a million immigrants over a total population of 6.5 millions inhabitants set the authorities the problem of finding sizeable new areas for housing, consumer services, and employment in a country that lacks the abundance of land that characterizes North America. On the other hand, Israel does have a tradition of centralized planning within a democratic framework, even though decision-making powers are less centralized than the formal legal and bureaucratic structures would suggest. In fact, since the mid-1980s local government authorities have become increasingly dependent on self-generated revenues, thus strongly competing to attract commercial and industrial land uses (Razin, 1998; 2004). This context of high demand for land and eroding central control, competition between municipalities, and market forces explain the dynamic economic deconcentration identified in Tel Aviv, which largely represents that occurring on a smaller scale in Israel. The rapid deconcentration tends to favour the outer rings with proximity to major highways and highway junctions.

The Czech Republic can now be characterized, like the Mediterranean countries, as a decentralized liberal governance system. During the period of communism and central planning, there was a strong preference for the concentration of development in major urban centres. Investment and growth went into large housing and industrial complexes at the urban edge of medium and large cities. Since the beginning of the post-communist transition, the most important features of urban change in Prague and Brno can be characterized by the commercialization of the historic cores and adjacent areas of the inner cities, commercial and residential suburban- 
ization into the outer city and urban hinterland, and selective revitalization in inner city areas (Sýkora et al., 2000). The transition of the former socialist system into a decentralized decision-making system within a market economy with an aversion to central planning attracted new (foreign) investments in big-box hypermarkets and warehousing in particular. These firms consume a relatively large amount of land; they were situated outside the central cities, particularly around Prague. As the country's major command and control centre, deconcentration processes in Prague did not involve producer services or offices unless they were an integral part of retail or warehousing. Brno's economic development depends strongly on the reindustrialization that took place in the new industrial zones and the individual production plants in suburban areas. While non-residential suburbanization was driven by the demand of international firms expanding on Czech markets in the second half of the 1990s, residential suburbanization was driven by the (limited) investments of Czech households in a context of overall population stagnation. Despite the recent forceful dynamics in economic deconcentration, compared with the other European case studies the deconcentration patterns of both Prague and Brno can best be characterized as 'small' and 'concentrated'.

To end this section, we can conclude that offsetting the economic deconcentration patterns against the relevant types of governance system does not clearly confirm the assumptions about the impact of governance systems on deconcentration patterns. Large deviations can be found for the Dutch, British, and Czech cases, and Rome and Valladolid. Explanations of the variations in deconcentration patterns have to be sought in the various contextual factors, such as the scarcity of urban land, urban scenery, administrative fragmentation, and level of coherence. For the Netherlands, the relatively large-scale deconcentration was caused by the relatively large economic and employment growth, which led to heavy demands for land. However, the strong interventionist approach accommodated this growth in land-use concentrations. This approach is in contrast with that in Israel, where the huge demand for land for urban functions in a rather weak policy context resulted in the deconcentration of employment to the outer suburban zones. The (small) loss of jobs in central Rome in combination with the attractive urban scenery did not push economic functions out of the central city in the 1990s. One can wonder what will happen in this city when employment growth reaches the levels of Madrid and Tel Aviv. Although deconcentration is substantial, the relatively large investments in the built environment of Madrid have tempered the deconcentration processes in this metropolitan area. Just like Rome, the Czech Republic could also face serious deconcentration processes the moment the economy becomes more integrated into the international economy and economic prosperity rises.

In addition, the demand for urban land and urban scenery, administrative fragmentation, and a lack of coherence seem to be explanatory factors for the deviations. In the UK, the fragmentation of administration and the absence of integrative (sub) regional plans contributed to the relatively heavy domination of outer suburban zones in Bristol and Southampton. The desire to stimulate economic growth, which overruled the negative impact on environment and accessibility 
(Hills et al., 2005), also contributed to the growth of the outer suburban zones in these British cases.

\section{4 \\ Quality of life and policy impacts}

The quality of life in metropolitan areas can be seriously affected by economic deconcentration. This has three dimensions: economic, social, and environmental. The economic dimension consists of the supply of new jobs, infrastructural costs, transport and travel costs (Cervero, 1989, 1996; Cervero \& Kang-Li Wu, 1998), and tax incomes. The social dimension refers to access to jobs and amenities (Van Ham et al., 2001), choice of services, and so forth. Environmental quality-of-life indicators include the loss of open land, traffic pollution (Naes and Sandberg, 1996), and nuisance and hazards associated with the proximity of certain economic activities to residential areas (Garb et al., 2004). As mentioned in chapter 1, in contrast with residential deconcentration, relatively little is known about the impact of the economic variant of deconcentration on the quality of life. The aim of this section is to generate some insights into these effects and to link them to the governancesystem typology mentioned in Table 10.3. We hypothesised that the extent and types of policy put in place to influence the quality of life depends on the type of governance system. In general terms, we expected that the comprehensive welfare states (Denmark and the Netherlands) would have policies in place to manage the economic, social, and environmental outcomes of economic deconcentration. These countries will influence the effects through land-use controls/regulatory growth controls and by applying policy instruments capable of avoiding unequal outcomes. These policy initiatives could also be found, although marginally, in central liberal states (United Kingdom). In contrast, the decentralized liberal systems (Czech Republic, Israel, Italy and Spain) will be characterized by much fewer efforts to influence the quality of life and the policies they apply will be much more 'market-based', such as setting up financial penalties and incentives to stimulate the regeneration of the older urban centres.

A thorough test of the quality-of-life impacts of various economic deconcentration patterns has shown that the most sensitive quality-of-life issue is accessibility; this refers to congestion and proximity to work and shopping centres. A change in deconcentration configuration is likely to elicit a change in these social indicators, a change which would be much greater than for economic indicators, such as income, local taxes or local employment, for example. There are significant policy implications in the areas of commuting and households' residential and employment choices (Felsenstein, 2005).

As expected, only in Denmark, the Netherlands, and the United Kingdom is the management of economic deconcentration an explicit policy goal. These countries do not mention the quality-of-life impacts explicitly, but they do refer to the sustainability outcomes of economic deconcentration in the form of diminishing accessibility, increasing congestion, and the declining viability and vitality of town 
centres (Hills et al., 2005). In the Netherlands, spatial planning policies have been fairly successful in managing economic growth. In the previous section, we mentioned the important role of the 'concentration' principle in this respect. Two other principles have contributed in particular to the quality of life of metropolitan areas: spatial coherence and spatial differentiation (Bogaerts et al. in this book). 'Spatial coherence' was aimed at stimulating the development of a mixture of coherent urban activities in urban and suburban areas; 'spatial differentiation' focused on the preservation of open areas, the differentiation of residential environments, and the protection of residential functions against the nuisance and hazards of certain economic functions. Various land-use controls and regulation policies were applied to reach these aims (op. cit.). Nevertheless, monofunctional areas have been developed in the Northwing and Breda metropolitan areas. Furthermore, changing people's travel patterns through physical policies would seem to be difficult, if not impossible (Schwanen et al., 2004).

In the Danish case, the improved balance between workplaces and the pattern of human settlements did not prevent increasing commuting problems. Both the proportion of long-distance commuters and the average commuting distance increased. The lack of success in managing the location of workplaces based on the strategies used in regional planning is blamed for the increasing total transport and the share travelling by car. Nevertheless, the quality of life in Copenhagen seems to be high. Thanks to the Finger Plan, the metropolitan area has a relatively welldeveloped urban and green structure. The urban areas situated in the fingers have relatively good access to public transport. Retail regulations fostered the development of mixed functions in urban areas. Brownfield developments upgraded older urban structures (Hills et al., 2005). The wedges between the fingers give high access to green and natural scenery. In addition, there are plentiful stretches of coastal areas and beaches near at hand. As in the Netherlands, the credit for the current environmental quality must be attributed to the fact that Denmark has a long tradition of environmental concern, well-developed legislation, a well-established environmental movement, and active political interest in sustainable development on all administrative levels. This environmental consciousness is also underlined by Denmark's contribution to 'Local Agenda 21' activities (Matthiessen et al., 2002).

In the United Kingdom, the management of economic deconcentration is an explicit policy aim. However, compared with Denmark and the Netherlands, this tradition is relatively young. From the mid-1990s onwards, policies aimed at reducing deconcentration processes in order to promote sustainable development have increased in popularity (Hills et al., 2005). Relevant policy instruments are the Green Belt, which preserves open space, and the Sequential Approach, which favours retail development in town centres. Nevertheless, large-scale deconcentration to suburban zones is dominant in the British metropolitan areas. Economic deconcentration in Bristol and Southampton has improved the accessibility of employment, especially for the residents of the urban fringe (Smith in this book) However, the other side of the deconcentration coin shows that, between 1981 and 2001 , there was a massive increase in the number of commuting kilometres trav- 
elled and in the average distance travelled for work, despite the converging spatial distribution of housing and employment. Serious environmental damage has ensued in the form of noise, congestion, and carbon emissions. So while there has been a broadly positive economic impact of economic deconcentration (the successful economic restructuring of the metropolitan areas of Bristol and Southampton), both the social and environmental consequences of economic deconcentration have been less well managed (op. cit.). In neither of these metropolitan areas is the fragmented governance system capable of facilitating the management of the negative consequences of economic deconcentration. For that purpose, the resurgence interest in sub-regional planning could be an important step forwards (op. cit.).

In the countries that belong to the decentralized liberal governance systems group, the management of economic deconcentration is not an explicit planning goal (Hills et al., 2005). In Israel, the spatial plans are based on the principle of limiting sprawl and concentrating urban developments (not explicitly economic developments) in relatively large and dense suburbs. From an economic point of view, the accelerated suburbanization of economic activities has not so far eroded the fiscal soundness of the Tel Aviv municipality. On the contrary, the relatively small population and accelerated suburbanization of the population have helped maintain a very high ratio of business to residential land uses. Moreover, out-migration from the central city has not been associated with an increasing concentration of poor people in the city. Tel Aviv remained attractive for the prosperous population categories (Razin \& Shachar in this book).

In Spain, economic deconcentration has to a certain extent been stimulated by the local government authorities in order to boost their economies (Hills et al., 2005). In both Spanish cases, but mainly in Madrid, this deconcentration process generated a high increase in the demand for inter-municipal mobility. In addition to their mononuclear form, the centripetal traffic network and increasing car ownership contributed to an increase in congestion and pollution in both central cities. In general, planning at the metropolitan or regional scale lacks efficiency in achieving a better adjustment in the territorial assignation of employment and housing by subordinating local planning to supra-municipal objectives. Local planning has mainly pursued housing-related aims, while the location of companies appears to conform to different criteria (Angelet, 2000). There are few explicit policies to influence the quality of life impacts in Spain.

The mismatch between residential deconcentration during the $1980 \mathrm{~s}$ and the limited employment deconcentration in the Italian cases resulted in thick traffic flows and congestion on the road networks. During the rush hour in Rome, private transport represents 67 percent of total trips and the motorization rate is one of the highest in the world, generating problems of air pollution and noise (Montanari et al. in this book). The poor quality of the metropolitan public transport system and the absence of integrated planning for economic and residential deconcentration, which is reinforced by the lack of a powerful metropolitan authority, have contributed to these quality-of-life problems. Nevertheless, the relatively small scale of economic deconcentration in Rome and Chieti-Pescara 
explains why these metropolitan areas so far face relatively limited environmental and social problems. Rome's City Master Plan aimed at developing a polycentric city could help limit the detrimental effects of future employment growth on the quality of life.

In the formerly centrally-planned economies, the ownership of assets was concentrated in the state, earnings inequality in the dominant state sector was low, and public policies were designed to limit income differences (Aghion \& Commander, 1999). Given the initial conditions at the start of the transition, it is hardly surprising that the liberalization of the economy and the introduction of market processes led to greater income inequality (Nee \& Peng, 1996). The spatial mismatch between jobs and residences is emerging in Prague and Brno (Sýkora \& Ouřednícek in this book), contributing to increased travel in metropolitan areas and negative effects on the quality of life. The compact character of the former socialist cities is changing through the rapid commercial and residential suburbanization that now threatens sustainable metropolitan development in the Czech Republic.

The case studies discussed in this book show that the issue of the management of the quality-of-life effects of economic deconcentration has only been contended with in the comprehensive welfare- and centralized-liberal states. These countries applied various land-use controls and regulation policies to stimulate the positive and diminish the negative quality-of-life aspects. Strategic plans such as the Finger Plan in Copenhagen and regulation policies such as the development of mixed land uses, preserving open landscapes, and retail regulations seem to have been highly successful from a quality-of-life perspective.

\section{5}

\section{Conclusions and policy implications}

Compared with North America, European employment deconcentration is a relatively young and small-scale process. Nevertheless, it is an issue, especially in regard to its quality-of-life effects. These are put high on the agenda of European politicians and policymakers. Economic deconcentration processes of consumer and producer services and manufacturing/construction within European large and medium-sized metropolitan areas have been analysed and discussed in the preceding national chapters and in this comparative chapter. Two hypotheses structured our discussion. The multi-dimensional centrality hypothesis is based on the idea that economic deconcentration is related to the position of a city in its economic cycle: deconcentration occurs first and most intensively in leading economic countries and in the largest cities. In the governance system hypothesis, it is assumed that the positioning on the deconcentration spectrum, varying from the archetypical American sprawl type to the European compact model, depends on the type of governance system. Besides these two hypotheses, the quality-of-life impacts of economic deconcentration and the effect of planning policies have been discussed. In this concluding section, we highlight our main findings and discuss some policy implications. 
The European experience with economic deconcentration as discussed in this book shows that economic deconcentration is a complex phenomenon and that the variations in deconcentration patterns in Europe are wide, probably wider than in North America. The complexity is apparent in various dimensions of economic deconcentration: stage, scale, and form. In accordance with the first hypothesis, the various case studies are to be found in various stages of economic deconcentration. The deconcentration processes in the North European metropolitan areas and Tel Aviv started much earlier than the 1990s when the processes started in the metropolitan areas of southern and eastern Europe. This deconcentration is shown by the dominance of suburban locations with respect to employment. As a consequence, the urban structure of the metropolitan areas of the economically leading countries has a much more polycentric character. The economies in southern and eastern Europe are lagging behind or catching up and they have a rather monocentric structure. In a world of intensifying globalization and integration, these economic deconcentration processes in metropolitan areas are expected to continue. Although this development means that the relevance of central cities in metropolitan areas will decline, in absolute terms employment in the central city is still increasing. In the 1990s, except for Chieti-Pescara and Tel Aviv, all central cities and even most centres in these central cities experienced an expansion of the number of jobs.

The fact that economic deconcentration processes started earlier in the metropolitan areas in northern Europe and Israel does not mean that, compared with other regions, the scale of deconcentration in these areas is much smaller. On the contrary; our analysis has shown that the scale, measured by the growth of employment in suburban zones as a percentage of total employment in 1990, was on the average higher. The growth of the national economies and, for Israel, the massive immigration of Jews stimulated the deconcentration of economic land uses. In southern Europe in the 1990s, only Spain was catching up quickly with the leading economies. This achievement can largely be explained by the improvement of the Spanish position within the economic cycle.

The driver for spatial reorganization that has received the largest share of attention in this book has been the governance and land-use planning regime. Based on the various characteristics of governance systems, we expected that deconcentration would have taken place on a smaller scale and in a much more concentrated form in comprehensive welfare state systems than in liberal regimes. This hypothesis is confirmed for the decentralized comprehensive welfare state case (Copenhagen), and three decentralized liberal state metropolitan areas (ChietiPescara, Tel-Aviv, and Madrid). However, large deviations can be found for the other 8 metropolitan areas. The deconcentration in the Northwing of the Randstad and Breda is much more substantial than expected, but concentrated. In contrast, the large-scale deconcentration in Bristol and Southampton is less concentrated. Finally, Rome, Prague, Brno, and Valladolid all experienced unexpected smallscale but concentrated developments. 
The European experience shows that a comprehensive explanation can be found through combining both hypotheses and by taking into account the specific contexts in which the economic activities and interventions of public authorities develop. This is illustrated in the penetration of hypermarkets in eastern European countries. This penetration is largely led by German (Metro/Makro), British (Tesco) and French (Auchan and Carrefour) multinationals. These post-communist countries offer many opportunities for economic growth because of the transition of the former socialist system into a market economy. However, these investments in hypermarkets are also favoured by the strong aversion to central planning in these countries (see Garb and Sýkora \& Ouřednícek in this book). These developments in retailing are further supported by the residential and car-ownership decisions of households. The Netherlands is another example. The unexpected large-scale deconcentration in this country is caused by the relatively large economic and employment growth, which stimulated high demands for land. However, the scarcity of land in combination with a strong interventionist approach stimulated the development of relatively heavy clusters of land-use concentrations in central cities and suburban locations. In contrast, limited economic growth in Rome caused a (small) loss of employment in the central city. Economic functions could be kept in the central city of Rome by the attractive urban scenery. The same is true for the large investments in the built environment of Madrid, which limited economic deconcentration. In addition to the scarcity of land and the urban scenery, the level of administrative fragmentation and coherence is a relevant contextual factor. This is exemplified by the UK, where administrative fragmentation and the absence of integrative (sub) regional plans contributed to the relatively large domination of outer suburban zones in Bristol and Southampton. The national consensus to restrict urban deconcentration to further a sustainable development melted away under the pressure to stimulate economic growth (Hills et al., 2005).

Although the relationship between type of governance system and pattern of economic deconcentration deviated from our assumptions, the extent and the types of policy in place to influence the quality of life are largely in accordance with our expectations. The case studies show that the issue of the management of the quality-of-life effects of economic deconcentration is only dealt with in the comprehensive welfare and centralized liberal states. Various land-use controls and regulation policies were applied in order to influence the quality of life. Strategic plans such as the Finger Plan in Copenhagen and the development of mixed land uses, preserving open landscapes, and retail regulations were highly successful in this respect.

On the basis of our findings, we now address the issue of the future outlook for the economic deconcentration of the metropolitan areas discussed in this book. We have concluded that changes in the role of metropolitan areas can have a major impact on the demand for land for economic functions. From a quality-of-life perspective, the accommodation of this demand for land seems to be relatively unproblematic for countries that are familiar with comprehensive welfare planning. Countries like Denmark and the Netherlands have for a long time had a 
suitable planning organization and set of policies to improve the quality of life in their metropolitan areas. However, driven by the constant need to enhance competitiveness to reach higher levels of economic development, in both countries liberal-conservative and liberal-Christian governments stress the responsibility for planning of lower-level of administrative authorities and a liberalization of planning regulations. This delegation could limit the effectiveness of public authorities to achieve sound spatial configurations of economic functions from a quality-of-life perspective. The substitution in the Netherlands of the compact-city planning concept by the network-city concept, which offers the opportunity to develop new locations along infrastructural networks between major central cities, could lead to such a situation.

In contrast, the Mediterranean and East European countries are less wellequipped with appropriate planning organizations and policies to manage economic deconcentration and its quality-of-life impacts. In these contexts, market mechanisms, which bring together demand and supply for land, largely conduct the spatial configurations of land use and quality of life. This pressure on land is relatively unproblematic in a situation where there is an abundance of land or where demand for land is not very big, as in the Italian and Czech cases. However, the moment these metropolitan areas face large growth in employment, the pressure on land markets will increase. In a liberal state, the responsible public authorities have neither the ability nor the desire to protect or improve the quality-of-life in their jurisdictions. In such a situation, outer suburban developments or even American sprawl and the associated economic, social, and environmental costs could develop. This situation is exemplified by Madrid, where in spite of large investments in the central city, employment in the outer suburban zone has grown substantially. This vulnerability could be diminished when these countries become more inspired by the North European countries to curb economic deconcentration processes and its negative quality-of-life impacts.

\section{Notes}

\footnotetext{
${ }^{1}$ After the death of the dictator Francisco Franco in 1975, the current democratic Constitution was approved in a referendum in 1978 and the first democratic municipal governments were in power following the April 1979 elections.

${ }^{2}$ Under the Spanish Constitution of December 27th 1978, Spain became a parliamentary monarchy based on social values, democracy, and the rule of law. The previous centralized regional structure was replaced by a new model of Autonomous Regions, provinces ( 50 in all), and municipalities. The Autonomous Regions (17 plus the autonomous cities of Ceuta and Melilla) have their own legal identity. The regions considered distinctive for linguistic, cultural or historical reason have received a greater transfer of powers from central government. Since the 1980s Spain has become one of the most politically decentralized countries in Europe; because of that seventeen regional governments were fully competent to deal with town and country planning regulations.
} 


\section{References}

Aghion P, Commander S (1999) On the dynamics of inequality in the Transition. Econ Tran 7(2):275-298

Angelet Cladellas J (2000) La descentralización del empleo y de la residencia en las áreas metropolitanas de Barcelona y Madrid. Urban 4:124-144

Bontje M (2004) Sustainable new economic centres in European metropolitan regions: a stakeholders' perspective. Eur Plann Stud 12(5):703-722

Castells M (1996) The rise of the network society. Blackwell Publishers, Oxford

Cervero R (1989) Jobs-housing balancing and regional mobility. J Am Plann Assoc 55:136-150

Cervero R (1996) Jobs-housing balancing revisited: trends and impacts in the San Francisco Bay Area. J Am Plann Assoc 62(4):492-511

Cervero R, Kang-Li Wu (1998) Subcentring and commuting: evidence from the San Francisco Bay Area, 1980-1990. Urban Studies 35(7):1059-1076

Clark WAV (2000) Monocentric to polycentric: new urban forms and old paradigms. In: Bridge G, Watson S (eds) A companion to the city. Blackwell Publishers, Oxford, pp 141-154

Esping-Anderson G (1990) The three worlds of welfare capitalism. Princeton University Press, Princeton, NJ

Evers D (2002) The rise (and fall?) of national retail planning. Tijdschrift voor economische en social geografie $93(1): 107-113$

Felsenstein D (2005) Translating economic land use deconcentration into quality of life impacts, Deliverable 05 (Final Report), SELMA project, Hebrew University, Jerusalem

Friedmann J (1986) The world city hypothesis. Dev Change 17:69-83

Garb Y, Van Kamp I, Kuijpers M, Oưedníccek M, Sýkora L (2004) Quality of life indicators, Deliverable 02, SELMA project

Garreau J (1991) Edge city: life on the new frontier. Anchor Books, Doubleday, New York

Graham S, Marvin S (2001) Splintering urbanism. Networked infrastructures, technological mobilities and the urban condition. Routledge, London

Halbert L (2004) The decentralization of intrametropolitan business services in the paris region: patterns, interpretation, consequences. Econ Geo 8(4):381-404

Hills S, Atkinson R, Smith I (2005) WP8 Policy analysis and prescriptions: policy analysis report. University of the West of England, Bristol

Ingram GK (1998) Patterns of metropolitan development: what have we learned? Urban Studies 35(7): 1019-1035

Janelle DG (1969) Spatial reorganization: a model and concept. Ann Assoc Am Geogr 59:348-364

Kloosterman RC, Musterd S (2001) The polycentric urban region: towards a research agenda. Urban Studies 38(4):623-633

Lang RE, LeFurgy J (2003) Edgeless cities: examining the noncentered metropolis. Housing Policy Debate 14(3):427-460

Larsen JN (2005) Governance, policy and determinants of economic land use deconcentration (WP6-report). Danish Building Research Institute, Copenhagen

López de Lucio R (2000) Madrid 1979-1999. Perfiles de una transformación urbana desconocida. Urban 4:106-123

Marcelloni M (2003) Pensare la città contemporanea. Il nuevo piano regolatore di Roma. RomaBari, Laterza, Roma 
Matthiesen CW, Søgaard H, Anderberg S (2002) Environmental performance and European cities: a new key parameter in the competition between metropolitan centres. In: Davies WKD, Townshend IJ (eds) Monitoring cities: international perspectives. International Geographical Union, Urban Commision, University of Calgary and University of Lethbridge, Calgary pp 119-142

MVROM (1988) Fourth spatial planning memorandum. Ministry of Housing, Physical Planning and the Environment, The Hague

MVROM (1991) Fourth spatial planning memorandum extra. Ministry of Housing, Physical Planning and the Environment, The Hague

Naes P, Sandberg SL (1996) Workplace location, modal split and energy use for commuting trips. Urban Studies 33(3):557-580

Nee V, Peng L (1996) Market transition and societal transformation in reforming state socialism. Annu Rev of Sociol 22:401-435

Parr JB (1999) The Metropolitan area in its wider setting. In: Summers AA, Cheshire PC, Senn L (eds) Urban change in the United States and Western Europe, comparative analysis and policy (Second edition). The Urban Institute Press, Washington, pp 215-242

Parr JB (2003) The polycentric urban region: a closer inspection. Regional Studies 38(3):231-240

Phelps NA, Parsons N (2003) Edge urban geography: notes from the margins of Europe's capital cities. Urban Studies 40(9): 1725-1749

Pred A (1977) City-systems in advanced economies. Hutchinson, London

Razin E (1998) Policies to control urban sprawl: planning regulations or changes in the "rules of the game". Urban Studies 35:321-340

Razin E (2004) Needs and impediments for local government reform: lessons from Israel. Journal of Urban Affairs 26:623-640

Sassen S (1991) The global city. Princeton University Press, Princeton, NJ

Schwanen T, Dijst M, Dieleman FM (2004) Policies for urban form and travel: The Netherlands experience. Urban Studies 41(3):579-603

Sýkora L, Kamenický J, Hauptman P (2000) Changes in the spatial structure of Prague and Brno in the 1990s. Acta Universitatis Carolinae Geographica 35(1):61-76

Van Ham M, Hooimeijer P, Mulder CH (2001) Urban form and job access: disparate realities in the Randstad. Tijdschrift voor Economische en Sociale Geografie 92(2):231-246

Wallerstein I (1979) The capitalist world economy. Cambridge University Press, Cambridge 